\title{
İmidacloprid'e Maruz Bırakılan Sazan (Cyprinus carpio) Yavrularının Bazı Biyokimyasal Özelliklerindeki Değişimler
}

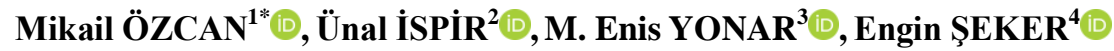 \\ ${ }^{1}$ Kahramanmaraş Sütçü İmam Üniversitesi, Ziraat Fakültesi Su Ürünleri Bölümü, Kahramanmaraş, Türkiye. \\ ${ }^{2}$ Malatya Turgut Özal Üniversitesi, Doğanşehir Vahap Küçük MYO, Malatya, Türkiye \\ ${ }^{3}$ Frrat Üniversitesi, Su Ürünleri Fakültesi, Elazı ̆̆, Türkiye \\ ${ }^{4}$ Munzur Üniversitesi, Su Ürünleri Fakültesi, Tunceli, Türkiye
}

*Sorumlu Yazar: mikailozcan@ksu.edu.tr

Geliş 07 Ağustos 2020; Kabul 17 Haziran 2021; Basım 01 Eylül 2021.

Alıntılama: Özcan, M., İspir, Ü., Yonar, M. E., \& Şeker, E. (2021). İmidacloprid’e maruz bırakılan Sazan (Cyprinus carpio)
yavrularının bazı biyokimyasal özelliklerindeki değişimler. Acta Aquatica Turcica, 17(3), $440-444$.
https://doi.org/10.22392/actaquatr.729034

Özet

Bu çalışmada imidacloprid'in sazan yavrularının bazı biyokimyasal parametrelerine olan toksik etkisinin belirlenmesi amaçlanmaktadır. Araştırmada ortalama ağırlığ $0,34 \pm 0,03 \mathrm{~g}$ ve $2,97 \pm 0,21 \mathrm{~cm}$ boyunda olan sazan yavruları kullanıldı. Balıklar, imidacloprid'in 2,8 ve $5,6 \mathrm{mg} / \mathrm{L}$ konsantrasyonuna 4 ve 7 gün için maruz bırakıldı. Süre sonunda balıkların tüm vücudunda lipit, protein ve glikojen içeriği belirlendi. Test gruplarında çalışma sonuna kadar ölüm gözlenmedi. İmidacloprid uygulanan balıklarda protein ve glikojen miktarlarında önemli derecede azalma $(p<0,05)$ olduğu tespit edildi. Toplam lipit düzeyi, 7. günde $5,6 \mathrm{mg} / \mathrm{L}$ imidacloprid uygulanan grupta yüksek olduğu görüldü. Ancak bu değerin kontrol grubundan istatistiki olarak farklı olmadığı tespit edildi. Çalışmada elde edilen veriler, imidacloprid'in balıkların biyokimyasal parametrelerine toksik etki gösterdiğinin bir kanıtı olarak düşünülebilir.

Anahtar Kelimeler: Imidacloprid, Cyprinus carpio, glikojen, toplam protein, toplam lipit

Changes in the Some Biochemical Constituents in Fry of Common Carp (Cyprinus carpio) Exposed to Imidacloprid

\begin{abstract}
This study was conducted to investigate the possible toxic effects of imidacloprid biochemical parameters of carp. The fish (weight $0,34 \pm 0,03 \mathrm{~g}$, total length $2,97 \pm 0,21 \mathrm{~cm}$ ) were subjected to 2,8 and 5,6 $\mathrm{mg} \mathrm{L}^{-1}$ of Imidacloprid concentration for 4 and 7 days. Alterations were observed in glycogene, total protein, and total fat activities in the whole body of carp. No mortalities occurred in any group during the test. The glycogene and total protein levels in imidacloprid treated fishes were significantly $(\mathrm{p}<0,05)$ lower than the control in all the concentrations. Total fat levels were higher in imidacloprid treatment groups, which were not significantly different. This study was conducted to investigate the possible toxic effects of imidacloprid biochemical parameters of carp.
\end{abstract}

Keywords: Imidacloprid, carp, Cyprinus carpio, glycogene, total protein, fat

\section{GíRiș}

Son yarım asırlık süre içerisinde özellikle modern tarımsal uygulamalarda çeşitli hastalık ve zararlılara karşı kimyasal ilaçların kullanılmaktadır. Bu ilaçlar pratik, kolay ve etkili bir yöntem olduğu için kullanımı sürekli olarak artmaktadır (Göktürk, 2007; Tiryaki vd., 2010; Gül, 2017). İstenmeyen organizmaları yok etmek için zirai mücadelede kullanılan pestisitler suda, atmosferde ve toprakta birikerek çevre kirliliğine neden olmaktadır (İnce ve Bekbölet, 1991; MacMahon, 1994).

Pestisitler tüm canlılarda özelliklede insanlar da kronik ve akut zehirlenmelere, enzim faaliyetlerinde bozulmalara, sinir sisteminde tahribata, hücre membran yapısında değişmelere neden olmaktadır (Çakır ve Yamanel, 2005). Bu tür kimyasalların bilinçsiz ve aşırı kullanımı zararlı populasyonlarında bağışıklık mekanizmasının gelişmesine veya çevreye faydalı birçok türün yok olmasına neden olmaktadır (Yıldız vd., 2005). Bunlara ilaveten üremeyle ilgili bozukluklar, enzim aktivitesi üzerindeki değişiklikler, beslenme alışkanlıkları ve beslenme ile ilgili anormallikler, davranışlarda ve algılamada eksiklik gibi birtakım değişikler görülmektedir (Kitchin, 1984). 
Neonikotinoid bileşenler sınıfında olan Imidacloprid bir pestisittir (El-Gendy vd., 2010). Dünya üzerinde insektisit olarak hızla artan bir kullanıma sahiptir (Liu vd., 2010). Toprak içerisinde birikim etkisi ve hareket etme özelliğine sahip olup, 48-190 gün arasında yarılanma ömürleri vardır (Andaç, 2015). Yarılanma ömrü suyun 5,7 ve 9 pH'da 31 günden daha fazladır. İmidacloprid balıklarda toksit etkisi diğer canlılara göre kısmen düşüktür. Arılar, toprak böcekleri, beyaz sinekler, termitler gibi emicilerin kontrolü amacıyla İmidacloprid tohum, toprakta ve ağaç yapraklarında kullanılırlar (Buckingham vd., 1997).

Imidacloprid bir nörotoksin olup asetilkolin reseptörlerini bloke etme özelliğine sahiptir. Sucul ekosistemlere tarım arazilerinde akan sularla kontamine olarak kirletmektedir (Morrissey vd., 2015; Bonmatin vd., 2015; Karahan vd., 2017).

Imidacloprid ile yapılan akut ve kronik çalışmalar, bu pestisitin hayvan dokularında oksidatif ve biyokimyasal yolları etkileyebileceğini ve önemli zararlı etkileri olduğunu göstermiştir (Tomizawa ve Casida, 2005). Ancak, imidacloprid'in balıklardaki etkisi araştırılmış ve tam olarak ortaya konulamamıştır (Rajput vd., 2012; Desai ve Parikh 2013; Iturburu vd., 2017). İmidacloprid'in, sazan yavrularında lipit, protein ve glikojen düzeyine etkisi hakkında yayınlanmış herhangi bir rapor bulunmamaktadır. Bu çalışmada imidacloprid'in sazan yavrularının bazı biyokimyasal parametrelerine etkisi araştırılmıştır.

\section{MATERYAL ve YÖNTEM}

\section{Balık ve deneysel plan}

Sazan, Cyprinus carpio, (ortalama ağırlı̆̆ $0,34 \pm 0,03$ g), Devlet Su İşleri 9. Bölge Müdürlüğü Keban Balık Üretimi Şube Müdürlügü̈nden temin edildi. Ortam şartlarına adaptasyonlarının sağlanması için 2 hafta beklenilmiştir. Cam akvaryumlara konan balıklara bir hava pompası vasıtasıyla sürekli olarak hava verilmiştir. Balıklar ticari bir balık yemi (\% 40 protein, \% 11 yağ, \% 10,1 ham kül, \% 1,3 ham selüloz, \% 2,4 kalsiyum, \% 1,5 fosfor, \% 0,3 sodyum içeren 0,6 NM granül yavru yemi) ile günlük olarak beslenmiştir. Çözünmüş oksijen, sicaklık, pH, amonyum ve nitrit düzeyleri çalışma boyunca kontrol edilerek kabul edilebilir değerler arasında olması sağlanmıştır.

Balıklar her grupta 25 balık olacak şekilde 3 gruba ayrılmıştır. Birinci gruba, kontrol grubu olarak herhangi bir işlem yapılmamıştır. Diğer iki gruba ise sırasıyla 2,8 ve $5,6 \mathrm{mg} / \mathrm{L}$ imidacloprid (Tyor ve

Harkrishan 2016) ilave edilmiştir. Balıklar 96 saat ve 168 saat (7 gün) (OECD, 2019) için bu konsantrasyonlara maruz bırakılmıştır. Deney iki tekerrür olacak şekilde yapılmıştır. Her grupta 25 balık olmak üzere toplamda 150 balık kullanılmıştır. Deney süresi sonrasında balıklar anestezik bir madde $(50 \mathrm{mg} / \mathrm{L}$, benzokain) (Hseu ve vd., 1998) ile anestezi yapılmış ve tüm vücut alüminyum folyolar içinde $-20{ }^{\circ} \mathrm{C}$ 'de biyokimyasal işlemler yapılana kadar muhafaza edilmiştir. Balık kullanımı ve deneysel protokol KSÜZİRHADYEK Hayvan Etik Kurulu tarafindan onaylanmıştır (Protokol no: $2017 / 01)$.

\section{Biyokimyasal testler}

Toplam protein tayini Plummer (1971)'e göre \%10 trikloroasetik asitile homojenize edilen tüm vücut dokusu gerekli işlemler yapıldıktan sonra Folin-phenolreagent kullanarak Lowry vd. (1951)'nın bildirdiği metoda göre gerçekleştirilmiştir.

Tüm vücut lipit düzeyi Folch vd. (1957)'nın bildirdiği kloroform: metanol tekniğine göre yapılmıştır.

Glikojen düzeyi ise Nicholas vd. (1956)'na göre antron kullanarak bir UV-Vis spektrofotometre kullanarak 620 nm'de glukoz standardına karşı tespit edilmiştir.

\section{İstatistik analiz}

Gruplar arası farklılıkları ortaya koymak için parametrik testler kullanılmıştır. Duncan testi ve tek yönlü varyans analizi (ANOVA) ile ortalama değerler arasındaki farklılıklar karşıllaştııılmıştır. Çalışma gruplarına ait verilerin ortalama ve standart hatası (Ortalama \pm S.Hata) belirlenmiştir.

\section{BULGULAR}

Kontrol ve deneysel imidacloprid uygulanan gruplardaki balıklarda herhangi bir fiziksel deformasyon, beslenme ve yüzme davranışlarında değişim ve ölüm kaydedilmemiştir.

İmidacloprid uygulanan sazan yavrularının tüm vücut dokusunda toplam protein aktivitesinde, doza bağlı olarak önemli derecede azalma $(\mathrm{p}<0,05)$ olduğu tespit edildi (Tablo 1 ve Tablo 2 ). Toplam 
protein düzeyi her iki deneysel grupta uygulamanın 4. gününde kontrol grubuna göre hafif bir azalma göstermişken 7. günde bu azalmanın istatistiki olarak anlamlı olduğu görülmüştür.

Toplam lipit düzeyinde ise istatistiki bir değişimin olmadığı ortaya konulmuştur ( $\mathrm{p}>0,05)$ (Tablo1 ve Tablo 2).

İmidacloprid'in 5,6 mg/L'lik dozunun uygulandığı grupta glikojen içeriliğinin, özellikle uygulamanın 7. gününde kontrol ve diğer imidacloprid grubuna göre önemli derecede bir azalmanın $(\mathrm{p}<0,05)$ olduğu tespit edilmiştir (Tablo1 ve Tablo 2 ).

Tablo 1. Sazan yavrularının toplam protein, lipit ve glikojen içeriğine 4. gün imidacloprid dozlarının etkisi

\begin{tabular}{lccc}
\hline \hline & \multicolumn{3}{c}{ 4. gün } \\
\hline & Kontrol & $\mathbf{2 , 8} \mathbf{~ m g} / \mathbf{L}$ & $\mathbf{5 , 6} \mathbf{~ m g} / \mathbf{L}$ \\
\hline Protein (mg/g) & $5,92 \pm 0,13^{\mathrm{a}}$ & $5,78 \pm 0,14^{\mathrm{a}}$ & $4,71 \pm 0,12^{\mathrm{b}}$ \\
Lipid (mg/g) & $0,79 \pm 0,12$ & $0,74 \pm 0,11$ & $0,81 \pm 0,14$ \\
Glikojen ( $\boldsymbol{\mu g} / \mathbf{g})$ & $3,73 \pm 0,3$ & $3,70 \pm 0,5$ & $2,70 \pm 0,4$ \\
\hline \hline
\end{tabular}

$\mathrm{X} \pm \mathrm{SH}$ : Aritmetik ortalama; \pm : Standart hatasi ${ }^{\mathrm{a}, \mathrm{b}}$ : Gruplar arasındaki fark

Tablo 2. Sazan yavrularının toplam protein, lipit ve glikojen içeriğine 7. gün imidacloprid dozlarının etkisi

\begin{tabular}{lccc}
\hline & \multicolumn{3}{c}{ 7. gün } \\
\hline & Kontrol & $\mathbf{2 , 8} \mathbf{~ m g} / \mathbf{L}$ & $\mathbf{5 , 6} \mathbf{~ m g} / \mathbf{L}$ \\
\hline Protein $(\mathbf{m g} / \mathbf{g})$ & $5,88 \pm 0,11^{\mathrm{a}}$ & $4,89 \pm 0,08^{\mathrm{b}}$ & $4,01 \pm 0,11^{\mathrm{c}}$ \\
Lipid $(\mathbf{m g} / \mathbf{g})$ & $0,82 \pm 0,11$ & $0,77 \pm 0,12$ & $0,78 \pm 0,12$ \\
Glikojen $(\boldsymbol{\mu g} / \mathbf{g})$ & $3,71 \pm 0,4^{\mathrm{a}}$ & $3,43 \pm 0,4^{\mathrm{ab}}$ & $2,49 \pm 0,3^{\mathrm{b}}$ \\
\hline \hline
\end{tabular}

$\overline{\mathrm{X}} \pm$ SH: Aritmetik ortalama; \pm : Standart hatası; ${ }^{\mathrm{a}, \mathrm{b}, \mathrm{c}}$ : Gruplar arasındaki fark

\section{TARTIŞMA ve SONUÇ}

Bu çalışmada; İmidacloprid'in 2,8 ve $5,6 \mathrm{mg} / \mathrm{L}$ konsantrasyonuna 4 ve 7 gün süre ile maruz bırakılan sazan (Cyprinus carpio) yavrularının bazı biyokimyasal parametrelerine olan toksik etkisi araştırılmıştır. Toplam protein $(\mathrm{mg} / \mathrm{mL})$, lipit $(\mathrm{mg} / \mathrm{g})$ ve glikojen $(\mu \mathrm{g} / \mathrm{g})$ değerleri incelenmiştir.

Inyang vd. (2018) tarafında yapılan çalışmada İmidacloprid'e maruz bırakıltığ 1 Heterobranchus bidorsalis'in bazı metabolitler (albümin ve toplam protein) ve elektrolitler $\left(\mathrm{Na}+, \mathrm{K}+, \mathrm{Ca}_{2}+\right.$ ) üzerindeki etkisini araştırmışıtır. Otuz beş yetişkin Heterobranchus bidorsalis (ortalama uzunluk, $22,43 \pm 2,42 \mathrm{~cm}$; ortalama ağırlık, $166,70 \pm 0,33 \mathrm{~g}$ ), 14 gün boyunca $0,28,0,42$ ve $0,56 \mathrm{mg} / \mathrm{L}$ imidacloprid konsantrasyonlarına maruz bırakmıştır. Toplam protein $0.00 \mathrm{mg} / \mathrm{L}$ 'de $5,00 \mu \mathrm{g} / \mathrm{L}, 0,28$ $\mathrm{mg} / \mathrm{L}$ 'de $10,25 \mu \mathrm{g} / \mathrm{L}, 0,42 \mathrm{mg} / \mathrm{L}$ 'de $20,50 \mu \mathrm{g} / \mathrm{L}$ ve $0,56 \mathrm{mg} / \mathrm{l}$ 'de $33,50 \mu \mathrm{gl}-1$ olarak ölçmüştür. Kontrol grubuna göre deney gruplarının karaciğerde önemli derecede toplam protein artmıştır $(p<0,05) . \mathrm{Bu}$ çalışmada ise İmidacloprid uygulanan sazan yavrularının tüm vücut dokusunda toplam protein aktivitesinde, konsantrasyona bağlı olarak önemli derecede azalma $(p<0,05)$ olduğu tespit edildi. Toplam protein düzeyi her iki deneysel grupta uygulamanın 4. gününde kontrol grubuna göre hafif bir azalma göstermişken 7. günde bu azalmanın istatistiki olarak anlamlı olduğu görülmüştür. $\mathrm{Bu}$ çalışmada ise, toplam protein seviyelerinde görülen azalmanın nedeni, serbest radikallerin proteinlerin tiyol gruplarına bağlanması ve protein yapısında farklı konfigürasyonlar geliştirmesi olabilir (Kayhan vd., 2017).

Lipitler balıklardaki başlıca enerji deposu ve mobilizasyonu yüksek enerji taleplerinin olduğunu

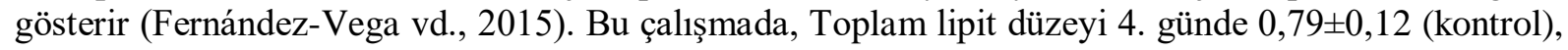
$0,74 \pm 0,11(2,8 \mathrm{mg} / \mathrm{L}), 0,81 \pm 0,14(5,6 \mathrm{mg} / \mathrm{L}) ; 7$. günde $0,82 \pm 0,11$ (kontrol), $0,77 \pm 0,12(2,8 \mathrm{mg} / \mathrm{L})$, $0,78 \pm 0,12(5,6 \mathrm{mg} / \mathrm{L})$ olarak ölçülmüsşür. Toplam lipit düzeyinde ise istatistiki bir değişimin olmadığ ortaya konulmuştur $(\mathrm{p}>0,05)$. Yüksek hidrofobik özellikteki toksik maddeler lipit dokusu tarafindan hapsedildikleri için ilgili reseptörlerle etkileşime giremezler ve organizmaya herhangi bir zarar vermeden uzun süreler boyunca vücutta kalabilirler (Landrum ve Fisher 1999).

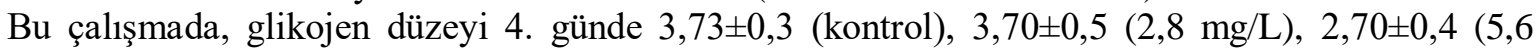
$\mathrm{mg} / \mathrm{L})$; 7. günde $3,71 \pm 0,4$ (kontrol), $3,43 \pm 0,4(2,8 \mathrm{mg} / \mathrm{L}), 2,49 \pm 0,3(5,6 \mathrm{mg} / \mathrm{L})$ olarak ölçülmüsstür. İmidacloprid'in $5,6 \mathrm{mg} / \mathrm{L}$ 'lik dozunun uygulandığı grupta glikojen içeriliğinin, özellikle uygulamanın 7. gününde kontrol ve diğer imidacloprid grubuna göre önemli derecede bir azalmanın $(p<0,05)$ olduğu tespit edildi. Bu, İmidacloprid'e maruz kalan balıkların genel bir cevabı gibi görünmektedir 
(Hori vd., 2006; Abdel-Hameid, 2007). Bu glikojen düşüşü İmidacloprid'in neden olduğu enerji harcamalarının bir göstergesi olabilir (Kayıs ve Emre, 2012).

$\mathrm{Bu}$ çalışma iki farklı konsantrasyondaki imidacloprid'in, farklı zaman periyodunda sazanların yavrularının tüm vücudunda protein, lipit ve glikojen aktivitelerinde olumsuz bir etki oluşturduğunu göstermiştir. Düşük konsantrasyonda olmasa da yüksek konsantrasyonda imidakloprid ile karşı karşıya kalan sazan yavrularında özellikle 7. günde biyokimyasal parametrelerde olumsuz etkiler gözlenmiş olması bu maddenin balıklarda toksik etki oluşturabileceğini göstermektedir. Fakat bu ifadenin doğruluğunun tam olarak ortaya konabilmesi için bu madde ile balıkların yüksek dozlarda muamele edilmesi ve uzun süre gözlenmesi gerekmektedir.

\section{TEŞEKKÜR}

$\mathrm{Bu}$ çalışma IV. International Multidisciplinary Congress of Eurasia (IMCOFE) 23-25 Ağustos 2017, Roma-İtalya'dan sözlü sunum olarak sunuldu.

\section{KAYNAKLAR}

Abdel-Hameid, N.A.H. (2007). Physiological and histopathological alterations induced by phenol exposure in Oreochromis aureus juveniles. Turkish Journal of Fisheries and Aquatic Sciences, 7: 131-138.

Andaç, Z. (2015). İmidacloprid uygulamasının mısır kültür formlarında yaprak anatomisi parametrelerine etkisi. Süleyman Demirel Üniversitesi, Fen Bilimleri Enstitüsü, Biyoloji Anabilim Dalı, Yüksek Lisans Tezi, $58 \mathrm{~s}$.

Bonmatin, J. M., Giorio, C., Girolami, V., Goulson, D., Kreutzweiser, D.P., Krupke, C., \& Noome, D.A. (2015). Environmental fate and exposure; neonicotinoids and fipronil. Environmental Science and Pollution Research, 22 (1), 35-67.

Buckingham, S., Lapied, B., Corronc, H., \& Sattelle, F. (1997). Imidacloprid Actions on Insect Neuronal Acetylcholine Receptors. The Journal of Experimental Biology, 200: 2685-2692.

Çakır, Ş., \& Yamanel, Ş. (2005). Böceklerde insektisidlere direnç. Gazi Üniversitesi Kırşehir Eğitim Fakültesi. 6 (1), 21-29.

Desai, B., \& Parikh, P., (2013). Biochemical Alterations on Exposure of Imidacloprid and Curzate on Fresh Water Fish Oreochromis Mossambicus and Labeo Rohita. Indian Journal of Forensic Medicine \& Toxicology, 7, 2: 87-91.

El-Gendy, K.S., Aly, N.M., Mahmoud, F.H., Kenawy, A., \& El-Sebae, A.K.H. (2010). The Role of vitamin c as antioxidant in protection of oxidative stress induced by imidacloprid. Food and Chemical Toxicology, 48: 215-221. https://doi: 10.1016/j.fct.2009.10.003

Fernández-Vega, C., Sancho, E., \& Ferrando, M.D. (2015). Energy reserves mobilization in the yellow eel as herbicide exposure effect. Chemosphere, 135: 94-100. https://doi.org/10.1016/j.chemosphere.2015.03.032

Folch, J., Lees, M., \& Stanley, G.H.S. (1957). A simple method for the isolation and purification of total lipides from animal tissues. The Journal of Biological Chemistry, 226(1):497-50.

Göktürk, F.A. (2007). Pestisit endüstrisi atıksularının fenton prosesi ile arıtımı. Selçuk Üniversitesi, Fen Bilimleri Enstitüsü, Çevre Mühendisliği Anabilim Dalı. Yüksek Lisans Tezi. 84s.

Gül, H. (2017). Türkiye'de kullanılan zirai ilaçların sağlığa etkileri. Nevşehir Hacı Bektaş Veli Üniversitesi, Sosyal Bilimler Enstitüsü, Sağlık Yönetimi Anabilim Dalı. Tezsiz Yüksek Lisans Dönem Projesi. 50s.

Hori, T.S.F., Avilez, I.M., Inoue, L.K., \& Moraes, G. (2006). Metabolical changes induced by chronic phenol exposure in matrinxã Brycon amazonicus (teleostei: characidae) juveniles. Comparative Biochemistry and Physiology - Part C: Toxicology, 143:67-72. https://doi.org/10.1016/j.cbpc.2005.12.004

Hseu J, Yeh S, Chu Y, Ting Y (1998) Comparison of efficacy of five anesthetics in Goldlined sea bream, Sparus sabra. Acta Zoologica Taiwanica 9 (1): 35-41.

Inyang, I.R., Izah S.C., \& Ntaka, C.M. (2018). Effect of imidacloprid on total protein, albumin and electrolytes in Heterobranchus bidorsalis. Environmental Analysis Ecology Studies, 4(5) 424-427.

Iturburu, F.G., Zömisch, M., Panzeri, A.M., Crupkin, A.C., Contardo-Jara, V., Pflugmacher, S., \& Menone, M.L. (2017) Uptake, distribution in different tissues and genotoxicity of imidacloprid in the freshwater fish Australoheros facetus. Environmental Toxicology and Chemistry, 36:699-708.

İnce, N., \& Bekbölet, M. (1991). Türkiye'de pestisit tüketimine ilişkin kirlenme öncelikleri, Türkiye'de Çevre Kirlenmesi Öncelikleri sempozyumu I, 551-570.

Karahan, A., Şahpaz, F., Kutlu, M.A., \& Karaca, İ. (2017). Effects Of Thiamethoxam On Vespula Germanıca (F.)(Hymenoptera: Vespidae). International Journal Of Agriculture, Environment and Food Sciences, $1(1), 49-55$.

Kayhan, F.E., Kaymak, G., Akbulut, C., \& Yön Ertuğ N.D. (2017). 2,4-D (Diklorofenoksiasetik Asit)'in Zebra balığı (Danio rerio Hamilton, 1822) solungaçlarında antioksidan enzimler ve lipid peroksidasyon seviyesi 
üzerine akut etkilerinin belirlenmesi. Trakya University Journal of Natural Sciences, 18(2): 143-148. https://doi.org/10.23902/trkjnat.294722

Kayıs, T., \& Emre I. (2012). Ağır Metal Stresinin Pimpla turionellae (Hymenoptera: Ichneumonidae)'nin Protein ve Glikojen Sentezine Etkileri. Ekoloji 21, 83, 61-67. https://doi.org/10.5053/ekoloji.2012.837

Kitchin, K.T. (1984). An enzymatic approach to biotransformation. Methods and Findings in Experimental and Clinical Pharmacology, 6: 303-310.

Landrum, P.F., \& Fisher S.W. (1999). Influence of lipids on the bioaccumulation and trophic transfer of organic contaminants in aquatic organisms. In: Arts MT, Wainman BC, eds. Lipids in Freshwater Ecosystems. New York: Springer; p.203-234.

Liu, G.Y., Miao,W., \& Ju, X.L. (2010). Mechanisms of Imidacloprid Resistance in Nilaparvata lugens by Moleculer Modelling. Chinese Chemical Letters, 21:492-495. https://doi.org/10.1016/j.cclet.2009.12.017

Lowry, O.H., Rosenbrough, N.J., Farr, A.L., \& Randall, R.J. (1951). Protein measurement with the Folin Phenol Reagent. The Journal of Biological Chemistry, 193, 265-275.

MacMahon, B. (1994). Pesticide residues and breast cancer. Journal of the National Cancer Institute, 86:572573.

Morrissey, C. A., Mineau, P., Devries, J. H., Sánchez-Bayo, F. Liess, M., Cavallaro, M. C., \& Liber, K. (2015). Neonicotinoid contamination of global surface waters and associated risk to aquatic invertebrates: $A$ review, Environment International, 74: 291-303. https://doi.org/10.1016/j.envint.2014.10.024

Nicholas, V., Carroll, R., Longley, W., \& Joseph, H.R. (1956). The determination of glycogen in liver and muscle by use of anthron reagent. The Journal of Biological Chemistry, 220: 583-593.

OECD, (2019). OECD Guidelines for the Testing of Chemicals Section 2: Effects on Biotic Systems Test No. 203: Fish, Acute Toxicity Testing, Paris, France.

Plummer, D.T. (1971). “An İntroduction to practical biochemistry”. McGraw-Hill Ltd., Maidenhead, England, $153 \mathrm{p}$.

Rajput, V., \& Singh, S. K. (2012). Comparative toxicity of Butachlor, Imidacloprid and Sodium fluoride on protein profile of the walking cat fish Clarias batrachus. Journal of Applied Pharmaceutical Science, 2, 121-124.

Tiryaki, O., Canhilal, R., \& Horuz S. (2010). Tarım ilaçları kullanımı ve riskleri. Erciyes Üniversitesi Fen Bilimleri Enstitüsü Dergisi, 26(2): 154-169.

Tomizawa, M., \& Casida, J.E. (2005). Neonicotinoid insecticide toxicology: mechanisms of selective action. Annual Reviews in Pharmacology and Toxicology 45:247-268.

Tyor, A.K., \& Harkrishan, K. (2016). Effects of imidacloprid on viability and hatchability of embryos of the common carp (Cyprinus carpio L.). International Journal of Fisheries and Aquatic Studies 4(4):385-389.

Yıldız, M., Gürkan, M., Turgut, C., Kaya, Ü., \& Ünal, G. (2005). Tarımsal savaşımda kullanılan pestisitlerin yol açtığı çevre sorunları, TMMOB Ziraat Mühendisleri Odası, Ziraat Mühendisliği VI. Teknik Kongresi, 2. 